\title{
ANALISIS KUALITAS AIR WADUK RIO - RIO DENGAN METODE INDEKS PENCEMARAN DAN TEKNOLOGI UNTUK MENGURANGI DAMPAK PENCEMARAN
}

\author{
Water Quality Analysis of Waduk Rio - Rio With Index Pollution Methods and Technology to Reduce the \\ Impact of Pollution \\ Dinda Rita K. Hartaja \\ Badan Pengkajian dan Penerapan Teknologi
}

\begin{abstract}
Abstrak
Waduk rio - rio merupakan waduk buatan yang terletak di Jakarta Timur. Saat ini kondisi waduk rio - rio tidak terawat, hal ini terlihat dari bagian outlet waduk berbusa yang menandakan adanya pencemaran. Oleh karena itu dilakukan pemantauan kualitas waduk yang bertujuan untuk mendapatkan gambaran kondisi kualitas waduk baik secara fisika, kimia, maupun mikrobiologi. Dari hasil pemantauan dan analisa data menggunakan indeks pencemaran, dapat diketahui bahwa tingkat pencemaran Waduk Rio - Rio pada periode I (musim kemarau) tergolong cemar sedang dengan nilai indeks pencemaran 5,542. Sedangkan pada periode II (musim transisi), nilai indeks pencemaran sebesar 11,069 dan tergolong cemar berat. Sumber pencemaran terbesar Waduk Rio - Rio adalah limbah domestik yang berasal dari aktivitas masyarakat sekitar waduk. Hal ini dapat diketahui dari tingginya parameter biologis seperti Fecal Coli dan Coliform. Agar dapat menurunkan tingkat pencemaran di Waduk Rio - Rio maka limbah domestik yang dibuang ke waduk perlu diolah terlebih dahulu. Salah satu teknologi pengolahan limbah cair domestik adalah Biofilter Anaerob - Aerob.
\end{abstract}

Kata Kunci : Indeks Pencemaran, Status Mutu Air, Biofilter Anaerob - Aerob

\begin{abstract}
Waduk Rio - Rio is an artificial ponds located in East Jakarta. Current condition of the waduk rio - rio is not maintained, its visible from outlet of the ponds foaming indicates pollution. Therefore, monitoring the quality of the ponds which describes the condition of good quality ponds in physics, chemistry, and microbiology. The results of the monitoring and analysis data using the pollution index, it can be seen that the pollution level of Waduk Rio - Rio in the first period (dry season) classified as moderate polluted by pollution index value of 5.542. While in the second period (transitional season), the value of the pollution index at 11.069 and classified as heavy polluted. The pollution sources of Waduk Rio - Rio is domestic wastewater which comes from community activities around the ponds. It can be seen from the high biological parameters such as Fecal Coli and Coliform. In order to reduce the level of pollution in the Waduk Rio - Rio, the domestic wastewater discharged into the ponds needs to be processed first. One of the domestic wastewater treatment technology is a biofilter Anaerobic - Aerobic.
\end{abstract}

Keywords : Pollution Indeks, Water Quality Indeks, Biofilter Anaerob - Aerob

\section{PENDAHULUAN}

Waduk Rio-Rio terletak di Jalan Pulo Mas Raya Kelurahan Kayu Putih, Jakarta Timur. Waduk Rio-Rio terbentuk secara buatan dengan luas yang ada saat ini hanya tinggal $\pm 3,85$ ha. Pesatnya pertumbuhan jumlah penduduk disekitar Waduk Rio-Rio memicu penyempitan lahan waduk. Sumber air berasal dari sumber alami dan buangan penduduk. Masukan air pada waduk berasal dari drainase Pulo Nangka, pada outlet waduk terdapat pintu air.

Kondisi air kontinyu dan kondisi waduk sangat tidak terawat. Pada bagian outlet air terlihat berbusa, hal ini menandakan adanya pencemaran detergen pada waduk tersebut. Proses pendangkalan terjadi karena pengurukan dan sedimentasi yang terbawa dari aliran air. Waduk ini berfungsi sebagai pengendali banjir dan resapan air. 
Kondisi lingkungan sekitar waduk Ria-Rio merupakan permukiman penduduk yang letaknya tidak beraturan. Sebagian lahan disekitar waduk RioRio digunakan untuk pertanian dan menggunakan air dari waduk untuk menyiram. Pada bagian utara waduk terdapat pompa pengatur banjir. Pada sisi barat waduk terdapat jalan raya dan jalan tol. Bagian utara waduk merupakan permukiman liar dan bagian timur serta selatan waduk terdapat permukiman penduduk. Warga dari permukiman tersebut membuang limbahnya langsung ke perairan waduk atau ke aliran Sungai masuk ke waduk.

Guna mendukung mengelola air waduk agar tidak tercemar, untuk memulihkan dan meningkatkan kualitas hidup masyarakat serta untuk mendapatkan gambaran kondisi kualitas air Waduk Rio - Rio baik secara fisika, kimia dan mikrobiologi, maka pada tahun 2015 ini dilaksanakan kegiatan Pemantauan Kualitas Sungai dan Waduk di Kota Administrasi Jakarta Timur.

Hasil pemantauan kualitas lingkungan, memperlihatkan telah terjadi penurunan kualitas air waduk rio - rio dengan tingkat pencemaran sudah mencapai ambang yang cukup serius. Perjalanan pembangunan kota yang pada tahap awalnya hanya ditekankan pada peningkatan produktivitas / pertumbuhan ekonomi mulai bergeser pada upaya upaya yang lebih proporsionil antara kepentingan ekonomi dan keseimbangan lingkungan melalui proses perencanaan pembangunan yang lebih partisipatif yang melibatkan peran serta para pelaku pembangunan (stake holder) dan masyarakat dalam setiap tahapan pembangunan guna terwujudnya tata pemerintahan yang baik (good governance) dan tata kelola lingkungan yang baik (good environmental governance).

\section{METODOLOGI}

Metode analisa data untuk menentukan status mutu air, baik air sungai, air danau / waduk, dan air tanah adalah dengan menggunakan Metode Indeks Pencemaran, sesuai dengan Keputusan Menteri Negara Lingkungan Hidup Nomor 115 Tahun 2003 tentang pedoman penetuan status mutu air.

\subsection{Metode Indeks Pencemaran}

Sumitomo dan Nemerow (1970), Universitas Texas, A.S., mengusulkan suatu indeks yang berkaitan dengan senyawa pencemar yang bermakna untuk suatu peruntukan. Indeks ini dinyatakan sebagai Indeks Pencemaran (Pollution Index) yang digunakan untuk menentukan tingkat pencemaran relatif terhadap parameter kualitas air yang diizinkan (Nemerow, 1974). Indeks ini memiliki konsep yang berlainan dengan Indeks Kualitas Air (Water Quality Index). Indeks Pencemaran (IP) ditentukan untuk suatu peruntukan, kemudian dapat dikembangkan untuk beberapa peruntukan bagi seluruh bagian badan air atau sebagian dari suatu sungai.

Pengelolaan kualitas air atas dasar Indeks Pencemaran (IP) ini dapat memberi masukan pada pengambil keputusan agar dapat menilai kualitas badan air untuk suatu peruntukan serta melakukan tindakan untuk memperbaiki kualitas jika terjadi penurunan kualitas akibat kehadiran senyawa pencemar. IP mencakup berbagai kelompok parameter kualitas yang independent dan bermakna.

\subsubsection{Prosedur Penggunaan}

Jika $L_{i j}$ menyatakan konsentrasi parameter kualitas air yang dicantumkan dalam Baku Mutu suatu Peruntukan Air (j), dan $C_{i}$ menyatakan konsentrasi parameter kualitas air (i) yang diperoleh dari hasil analisis cuplikan air pada suatu lokasi pengambilan cuplikan dari suatu alur sungai, maka $\mathrm{PI}_{\mathrm{j}}$ adalah Indeks Pencemaran bagi peruntukan (j) yang merupakan fungsi dari $\mathrm{C}_{\mathrm{i}} / \mathrm{L}_{\mathrm{ij}}$. Harga $\mathrm{Pl}_{\mathrm{j}}$ ini dapat ditentukan dengan cara :

a. Pilih parameter-parameter yang jika harga parameter rendah maka kualitas air akan membaik.

b. Pilih konsentrasi parameter baku mutu yang tidak memiliki rentang.

c. Hitung harga $C_{i} / L_{i j}$ untuk tiap parameter pada setiap lokasi pengambilan cuplikan.

d. Jika nilai konsentrasi parameter yang menurun menyatakan tingkat pencemaran meningkat, misal DO. Tentukan nilai teoritik atau nilai maksimum $\mathrm{C}_{\mathrm{im}}$ (misal untuk DO, maka $\mathrm{C}_{\mathrm{im}}$ merupakan nilai DO jenuh). Dalam kasus ini nilai $C_{i} / L_{i j}$ hasil pengukuran digantikan oleh nilai $C_{i} / L_{i j}$ hasil perhitungan, yaitu :

$$
\left(C_{i} / L_{i j}\right)_{\text {baru }}=\frac{C_{i m}-C_{i(\text { hasil pengukuran })}}{C_{i m}-L_{i j}}
$$

e. Jika nilai baku $\mathrm{L}_{\mathrm{ij}}$ memiliki rentang :

- Untuk $C_{i} \leq L_{i j}$ rata - rata

$$
\left(C_{i} / L_{i j}\right)_{\text {baru }}=\frac{\left[C_{i}-\left(L_{i j}\right)_{\text {rata-rata }}\right]}{\left\{\left(L_{i j}\right)_{\text {minimum }}-\left(L_{i j}\right)_{\text {rata-rata }}\right\}}
$$

- Untuk $\mathrm{C}_{\mathrm{i}}>\mathrm{L}_{\mathrm{ij}}$ rata - rata

$$
\left(C_{i} / L_{i j}\right)_{\text {baru }}=\frac{\left[C_{i \mathrm{i}}-\left(L_{i j}\right)_{\text {rata-rata }}\right]}{\left\{\left(L_{i j}\right)_{\text {maksimum }}-\left(L_{i j}\right)_{\text {rata-rata }}\right\}}
$$

f. Keraguan timbul jika dua nilai $\left(C_{i} / L_{i j}\right)$ berdekatan dengan nilai acuan 1,0 , misal $C_{1} / L_{1 j}=0,9$ dan $\mathrm{C}_{2} / \mathrm{L}_{2 \mathrm{j}}=1,1$ atau perbedaan yang sangat besar, 
misal $C_{3} / L_{3 j}=5,0$ dan $C_{4} / L_{4 j}=10,0$. Dalam contoh ini tingkat kerusakan badan air sulit ditentukan. Cara untuk mengatasi kesulitan ini adalah :

- Penggunaan nilai $\left(C_{i} / L_{i j}\right)$ hasil pengukuran kalau nilai ini lebih kecil dari 1,0.

- Penggunaan nilai $\left(\mathrm{C}_{\mathrm{i}} / \mathrm{L}_{\mathrm{ij}}\right)$ baru jika nilai $\left(C_{i} / L_{i j}\right)$ hasil pengukuran lebih besar dari 1,0 . Persamaan $\left(C_{i} / L_{i j}\right)_{\text {baru }}$ adalah sebagai berikut:

$$
\left(C_{i} / L_{i j}\right)_{\text {baru }}=1,0+P \cdot \log \left(C_{i j} / L_{i j}\right)_{\text {hasil pengukuran }}
$$

$P$ adalah konstanta dan nilainya ditentukan dengan bebas dan disesuaikan dengan hasil pengamatan lingkungan dan atau persyaratan yang dikehendaki untuk suatu peruntukan (biasanya digunakan nilai 5).

g. Tentukan nilai rata-rata dan nilai maksimum dari keseluruhan $C_{i} / L_{i j}\left(\left(C_{i} / L_{i j}\right)_{R}\right.$ dan $\left.\left(C_{i} / L_{i j}\right)_{M}\right)$.

h. Tentukan harga $\mathrm{PI}_{\mathrm{j}}$, dengan persamaan dibawah ini

$$
P I_{j}=\sqrt{\frac{\left(C_{i} / L_{i j}\right)_{M}^{2}+\left(C_{i j} / L_{i j}\right)_{R}^{2}}{2}}
$$

Evaluasi terhadap nilai PI adalah :

- $0 \leq \mathrm{Pl}_{\mathrm{j}} \leq 1,0$

- $1,0<\mathrm{PI}_{\mathrm{j}} \leq 5,0$

- $5,0<\mathrm{PI}_{\mathrm{j}} \leq 10,0$

- $\mathrm{PI}_{\mathrm{j}}>10,0$

\subsection{Lokasi dan Waktu Pengambilan Sampel}

Pada penelitian ini dilakukan pengambilan sampel di salah satu waduk / waduk yang terletak di kota administrasi Jakarta Timur, yaitu Waduk Rio Rio. Pengambilan sampel dilakukan dalam 2 periode. Periode 1 dilakukan pada bulan Agustus 2015 yang mewakili musim kemarau. Sedangkan periode 2 dilakukan pada bulan November 2015 yang mewakili musim transisi.

\section{HASIL PEMANTAUAN KUALITAS AIR WADUK RIO - RIO}

\subsection{Parameter Fisika}

Parameter fisik waduk meliputi kekeruhan, Daya Hantar Listrik (DHL), Zat padat terlarut (TDS) dan Zat Padat Tersuspensi (TSS). Kualitas fisik dari waduk Rio - Rio dapat kita lihat pada penjelasan berikut ini:

\subsubsection{Daya Hantar Listrik}

Tinggi rendahnya DHL disebabkan oleh tinggi rendahnya konsentrasi ion Garam Terlarut sehingga garam tersebut terionisasi. Hasil pemantauan DHL air waduk rio - rio untuk Perioda 1 bulan Agustus 2015 dan Periode 2 bulan Nopember 2015 dapat dilihat pada Gambar 3.1.

Gambar 3.1. Konsentrasi Daya Hantar Listrik Waduk Rio - Rio Tahun 2015

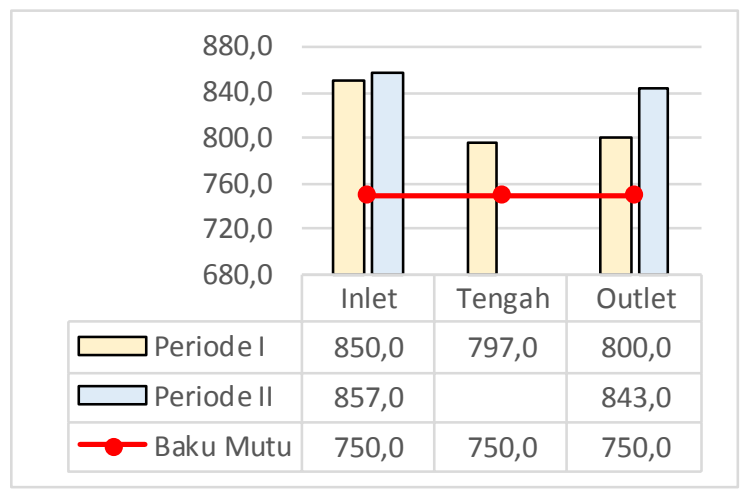

Sumber : BPLHD Jakarta Timur

Keterangan : Hasil Pemantauan 2015

Dari grafik di atas, menunjukkan bahwa hampir diseluruh segmen waduk rio - rio parameter Daya Hantar Listrik seluruhnya berada di atas baku mutu yang ditetapkan, yaitu di atas $750 \mu \mathrm{mhos} / \mathrm{cm}$.

Konsentrasi daya hantar listrik tertinggi terjadi pada inlet di kedua periode. Konsentrasi daya hantar listrik di inlet pada periode I sebesar $850 \mu \mathrm{mhos} / \mathrm{cm}$, dan periode II sebesar $857 \mu \mathrm{mhos} / \mathrm{cm}$.

\subsubsection{Total Dissolved Solids (TDS)}

Tinggi rendahnya TDS dipengaruhi kondisi lingkungan perairan seperti arus danau. Walaupun tidak bersifat toksik jika jumlahnya berlebihan akan meningkatkan kekeruhan. Hasil pemantauan TDS air waduk rio - rio untuk Perioda 1 bulan Agustus 2015 dan Periode 2 bulan Nopember 2015 dapat dilihat pada Gambar 3.2.

\section{Gambar 3.2. Konsentrasi TDS Waduk Rio - Rio Tahun} 2015

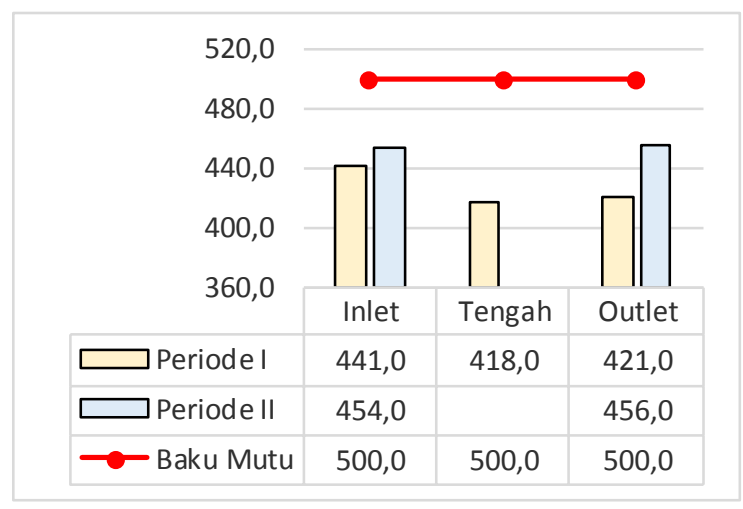

Sumber : BPLHD Jakarta Timur

Keterangan : Hasil Pemantauan 2015 
Dari grafik di atas dapat dilihat bahwa konsentrasi TDS diseluruh segmen waduk rio - rio masih dibawah standar baku mutu yang ditetapkan, yaitu $500 \mathrm{mg} / \mathrm{l}$.

\subsubsection{Total Suspended Solids (TSS)}

Hasil pemantauan konsentrasi TSS waduk rio rio untuk periode I dan II dapat dilihat pada gambar 3.3 berikut ini.

\section{Gambar 3.3. Konsentrasi TSS Waduk Rio - Rio Tahun 2015}

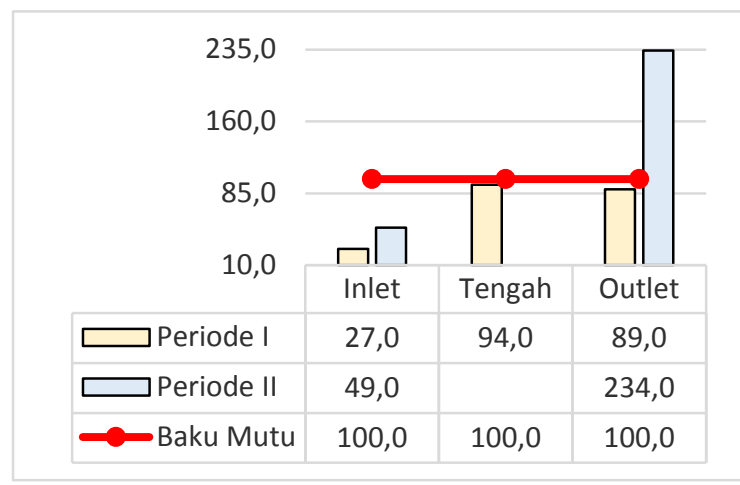

Sumber : BPLHD Jakarta Timur

Keterangan : Hasil Pemantauan 2015

Dari grafik di atas, menunjukkan bahwa pada periode I parameter TSS di seluruh segmen waduk rio - rio, berada di bawah baku mutu. Sedangkan periode II, terjadi peningkatan yang signifikan pada outlet waduk rio - rio. Konsentrasi outlet periode II sebesar $234,0 \mathrm{mg} / \mathrm{l}$, jauh di atas baku mutu yang ditentukan yaitu $100 \mathrm{mg} / \mathrm{l}$.

Tinggi rendahnya TSS dapat dipengaruhi oleh kondisi lingkungan perairan seperti ada tidaknya arus danau tersebut. Walaupun tidak bersifat toksik namun jika dalam jumlahnya berlebihan akan menghambat penetrasi radiasi matahari dan pada akhirnya mengganggu pertumbuhan biologi waduk.

\subsection{Parameter Kimia}

Kualitas kimia situ/waduk yang dipantau sesuai dengan PP No 82 Tahun 2001 tentang pengendalian pencemaran peruntukan perikanan dan peternakan (Kelas 3) sebanyak 36 parameter (hasil rinci terlampir). Parameter yang akan dibahas disini adalah parameter kunci yang dapat mempengaruhi kualitas air situ/waduk yang meliputi parameter BOD, COD, Organik, Phosphat, Detergent, dan Sulfida.

\subsubsection{Biological Oxygen Demand (BOD)}

Hasil pemantauan BOD waduk rio - rio periode I dan periode II tahun 2015 dapat dilihat pada gambar 3.4 berikut ini.
Gambar 3.4. Konsentrasi BOD Waduk Rio - Rio Tahun 2015

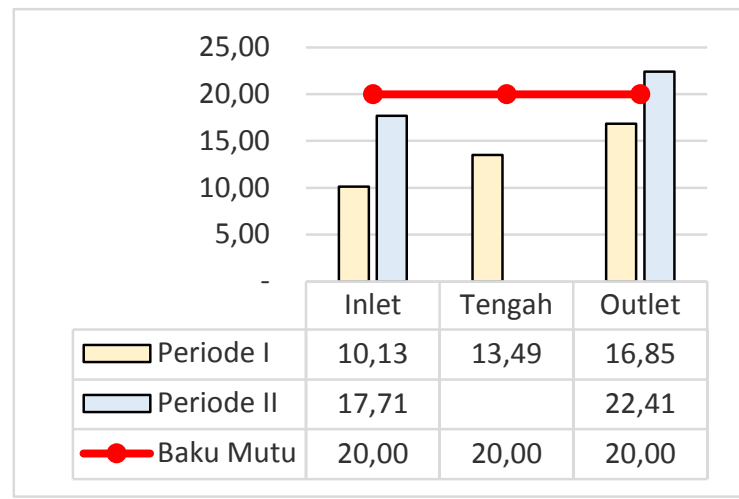

Sumber : BPLHD Jakarta Timur

Keterangan : Hasil Pemantauan 2015

Sama seperti TSS, konsentrasi BOD yang di atas baku mutu hanya pada outlet waduk rio - rio periode II, yaitu $22,41 \mathrm{mg} / \mathrm{l}$. Selain itu, konsentrasi BOD di semua segmen pada periode I dan II berada di bawah baku mutu yang ditetapkan, yaitu $20 \mathrm{mg} / \mathrm{l}$.

Tingginya konsentrasi BOD dapat menunjukkan adanya pencemaran polutan organik yang cukup tinggi di lokasi tersebut, sehingga kebutuhan akan oksigen untuk menguraikan bahan organik semakin tinggi.

\subsubsection{Chemical Oxygen Demand (COD)}

Hasil pemantauan konsentrasi COD waduk rio - rio untuk Perioda I dan II dapat dilihat pada gambar 3.5 berikut ini.

\section{Gambar 3.5. Konsentrasi COD Waduk Rio - Rio Tahun 2015}

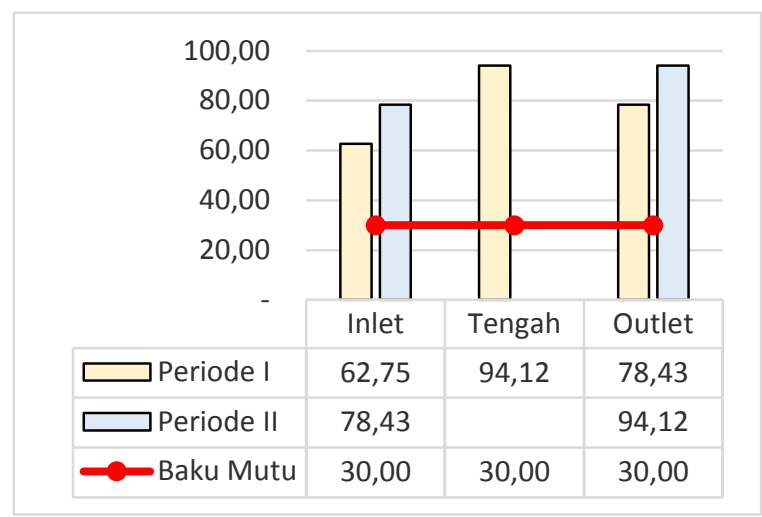

Sumber : BPLHD Jakarta Timur

Keterangan : Hasil Pemantauan 2015

Dari hasil pemantauan tersebut, dapat dilihat bahwa konsentrasi COD waduk rio - rio baik periode I ataupun periode II sudah melebihi standar baku mutu yang ditetapkan, yaitu sebesar $30 \mathrm{mg} / \mathrm{l}$. 


\subsubsection{Detergent}

Hasil pemantauan konsentrasi detergent waduk rio - rio untuk Perioda I dan II dapat dilihat pada gambar 3.6.

\section{Gambar 3.6. Konsentrasi Detergent Waduk Rio - Rio} Tahun 2015

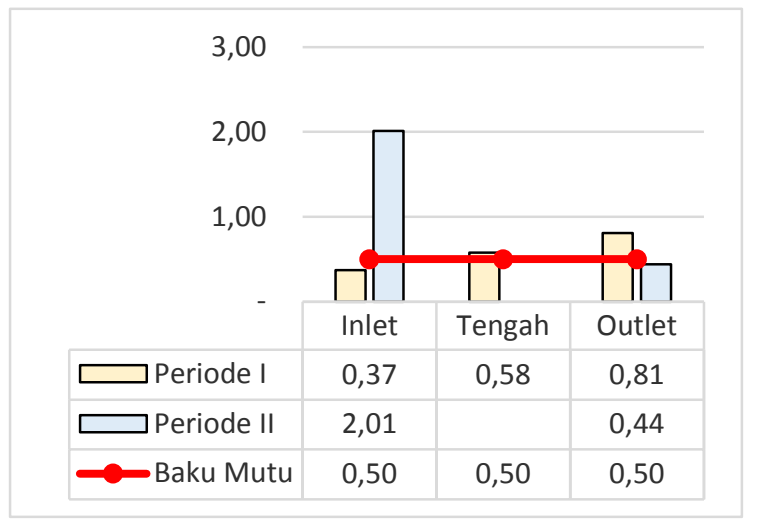

Sumber : BPLHD Jakarta Timur

Keterangan : Hasil Pemantauan 2015

Konsentrasi tertinggi terjadi pada inlet periode II, yaitu sebesar 2,01 mg/l. Hal ini terjadi karena pencemaran limbah domestik dari kegiatan penduduk di sekitar waduk rio - rio. Penduduk di sekitar waduk biasanya membuang limbahnya ke waduk, hingga pada inlet tersebut terlihat berbusa.

\subsection{Parameter Biologi}

Hasil pemantauan konsentrasi coliform dan fecal coli waduk rio - rio tahun 2015, dapat dilihat pada tabel 3.1 berikut ini.

Tabel 3.1. Hasil Pemantauan Coliform dan Fecal Coli Waduk Rio -Rio Tahun 2015

\begin{tabular}{|l|l|c|l|}
\hline \multicolumn{2}{|c|}{ Titik Pantau } & Periode I & Periode II \\
\hline \multirow{4}{*}{ Coliform } & Inlet & 600.000 & 7.200 .000 \\
\cline { 2 - 4 } & Tengah & 50.000 & \\
\cline { 2 - 4 } & Outlet & 37.000 & 4.500 .000 \\
\cline { 2 - 4 } & $\begin{array}{l}\text { Baku } \\
\text { Mutu }\end{array}$ & \multicolumn{2}{|c|}{20.000} \\
\hline \multirow{4}{*}{$\begin{array}{l}\text { Fecal } \\
\text { Coli }\end{array}$} & Inlet & 210.000 & 3.400 .000 \\
\cline { 2 - 4 } & Tengah & 10.000 & \\
\cline { 2 - 4 } & Outlet & 13.000 & 2.100 .000 \\
\cline { 2 - 4 } & Baku & \multicolumn{3}{|c}{4.000} \\
& Mutu & \multicolumn{2}{|c}{} \\
\hline
\end{tabular}

Sumber : BPLHD Jakarta Timur

Keterangan : Hasil Pemantauan 2015

Dari semua segmen yang dipantau, konsentrasi coliform dan fecal coli baik periode I maupun periode II, seluruhnya berada di atas baku mutu. Konsentrasi coliform dan fecal coli tertinggi terjadi di inlet pada periode II, yaitu 7.200.000 untuk coliform dan 3.400 .000 untuk fecal coli.

\subsection{Indeks Pencemaran Waduk Rio - Rio}

Indeks pencemaran merupakan salah satu metode untuk mempermudah kontrol terhadap pencemaran air yang ada. Penerapan sistem Indeks Pencemaran air memerlukan analisa yang tepat terhadap parameter yang ada sehingga tindakan perbaikan dapat dilakukan dengan efektif dan efisien. Hasil perhitungan Indeks Pencemaran Waduk Rio Rio tahun 2015 dapat dilihat pada Gambar 3.7.

\section{Gambar 3.7. Indeks Pencemaran Waduk Rio - Rio Tahun 2015}

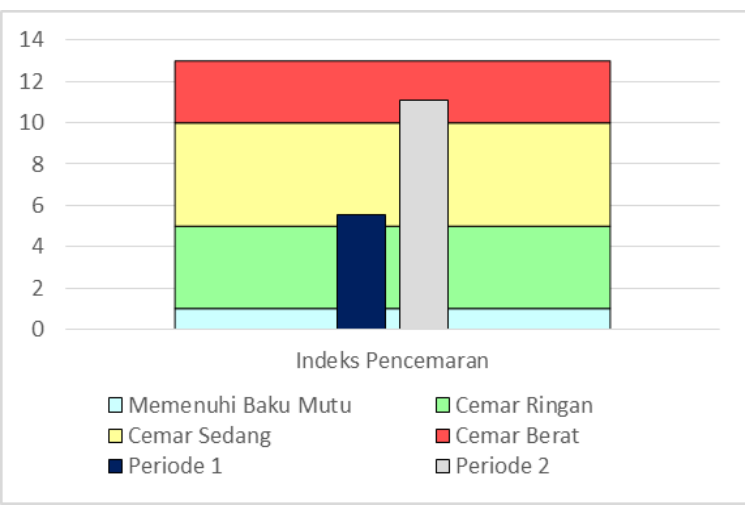

Sumber : BPLHD Jakarta Timur

Keterangan : Hasil Pemantauan 2015

Dari gambar 3.7 tersebut di atas dapat diketahui bahwa kondisi kualitas lingkungan Waduk Rio - Rio telah tercemar. Indeks pencemaran tertinggi terjadi pada periode II, yaitu 11,069 dengan kategori Cemar Berat. Sedangkan periode I, nilai Indeks Pencemarannya adalah 5,542 dengan kategori Cemar Sedang. Dari hasil perhitungan indeks pencemaran tersebut, terlihat bahwa tingkat pencemaran tertinggi terjadi pada musim transisi, dimana curah hujan masih sangat rendah dan merupakan akhir dari puncak musim kemarau. Hal ini dikarenakan kualitas waduk dipengaruhi oleh faktor cuaca, dimana waktu pengambilan sampel mempengaruhi kualitas air waduk. Ketika pengambilan sampel dilakukan pada saat musim kemarau, kualitas air waduk menjadi lebih buruk, karena pengenceran air hujan semakin sedikit. Sedangkan ketika musim penghujan kualitas air waduk menjadi lebih baik karena adanya faktor pengenceran dari air hujan.

Tingginya nilai Indeks pencemaran ini disebabkan karena belum dikelolanya Waduk Rio Rio baik perairan, kondisi lingkungan sekitar waduk maupun vegetasi sekitar. Faktor yang paling dominan yang mempengaruhi perhitungan Indeks Pencemaran pada kualitas lingkungan air waduk ini adalah 
bersumber dari pencemaran limbah domestik, hal ini dapat diketahui dari tingginya parameter biologis seperti Fecal Coli dan Coliform. Parameter BOD, COD, Detergen juga berpengaruh besar terhadap hasil perhitungan Indeks Pencemaran.Oleh karena itu diperlukan suatu sistem pengontrolan dan teknologi yang tepat dan efektif agar dapat meminimalisasi pencemaran waduk rio - rio. Salah satu teknologi yang dapat diterapkan dalam pengolahan limbah domestik adalah Biofilter Anaerob Aerob.

\section{PENGOLAHAN LIMBAH DOMESTIK DENGAN BIOFILTER ANAEROB DAN AEROB UNTUK MENGURANGI DAMPAK PENCEMARAN DI WADUK RIO - RIO}

Limbah domestik sebagian besar bersumber dari ketiadaan tangki septik. Hal ini membuat kadar oksigen terlarut dalam air berkurang dan menimbulkan kontaminasi bakteri $\mathrm{E}$ coli. Untuk mengatasi pencemaran badan air akibat limbah domestik, adalah dengan mengolah limbah cair tersebut secara individual (On Site Treatment) atau secara komunal sebelum dibuang ke badan lingkungan.

Dengan kapasitas $3 \mathrm{~m}^{3} /$ hari, maka reaktor biofilter anaerob - aerob dapat melayani sekitar 20 25 orang atau kurang lebih 5-6 rumah tangga. Reaktor ini terdiri dari beberapa bagian, yaitu bak pengendap awal, biofilter anaerob (anoxic), biofilter aerob, bak pengendap akhir, dan jika diperlukan dapat dilengkapi dengan bak kontaktor khlor.

Skema proses pengolahan limbah cair domestik dengan menggunakan sistem biofilter anaerob aerob ditunjukkan pada gambar 3.8 berikut ini.

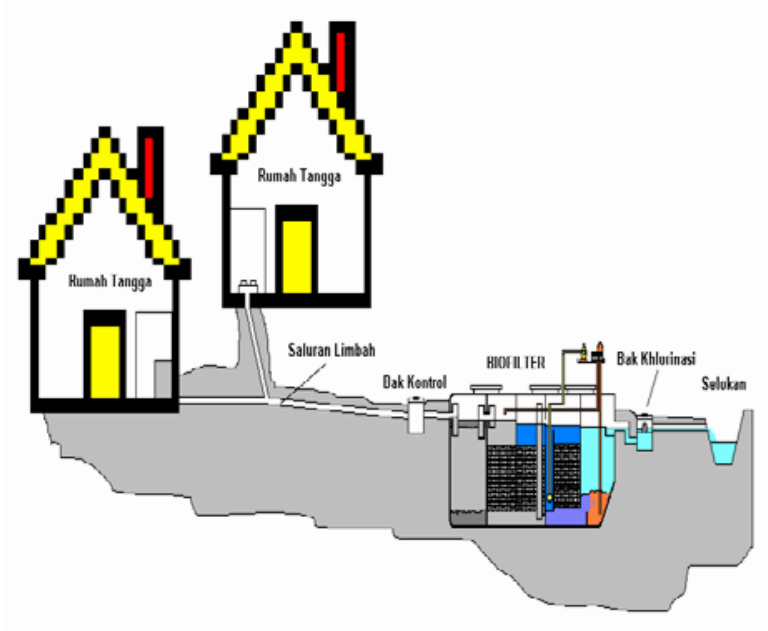

Gambar 3.8. Skema pengolahan limbah domestik menggunakan sistem biofilter anaerob - aerob Sumber : Kelompok Air PTL BPPT

Skema reaktor biofilter anaerob - aerob, dapat dilihat pada gambar 3.9 berikut ini.

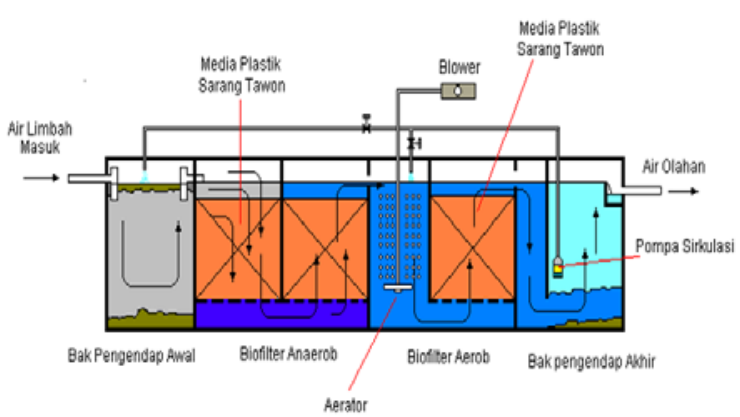

\section{Gambar 3.9. Skema Reaktor Biofilter Anaerob - Aerob}

Sumber : Kelompok Air PTL BPPT

\subsection{Proses Pengolahan Air Limbah dengan Proses Biofilter Anaerob - Aerob}

Seluruh air limbah dialirkan masuk ke bak pengumpul atau bak ekualisasi, selanjutnya dari bak ekualisasi air limbah dipompa ke bak pengendap awal, untuk mengendapkan partikel lumpur, pasir dan kotoran organik tersuspensi. Selain sebagai bak pengendapan, juga berfungsi sebagai bak pengontrol aliran, serta bak pengurai senyawa organik yang berbentuk padatan, pengurai lumpur (sludge digestion) dan penampung lumpur.

Air limpasan dari bak pengendap awal selanjutnya dialirkan ke bak kontaktor anaerob dengan arah aliran dari atas ke bawah, dan dari bawah ke atas. Di dalam bak kontaktor anaerob tersebut diisi dengan media dari bahan plastik tipe sarang tawon. Jumlah bak kontaktor anaerob terdiri dari dua buah ruangan. Penguraian zat-zat organik yang ada dalam air limbah dilakukan oleh bakteri anaerobik atau facultatif aerobik. Setelah beberapa hari operasi, pada permukaan media filter akan tumbuh lapisan film mikro-organisme. Mikroorganisme inilah yang akan menguraikan zat organik yang belum sempat terurai pada bak pengendap.

Air limpasan dari bak kontaktor anaerob dialirkan ke bak kontaktor aerob. Di dalam bak kontaktor aerob ini diisi dengan media dari bahan plastik tipe sarang tawon, sambil diaerasi atau dihembus dengan udara sehingga mikro-organisme yang ada akan menguraikan zat organik yang ada dalam air limbah serta tumbuh dan menempel pada permukaan media. Dengan demikian air limbah akan kontak dengan mikro-organisme yang tersuspensi dalam air maupun yang menempel pada permukaan media yang mana hal tersebut dapat meningkatkan efisiensi penguraian zat organik, deterjen serta mempercepat proses nitrifikasi, sehingga efisiensi penghilangan ammonia menjadi lebih besar. Proses ini sering di namakan Aerasi Kontak (Contact Aeration). 
Dari bak aerasi, air dialirkan ke bak pengendap akhir. Di dalam bak ini lumpur aktif yang mengandung massa mikro-organisme diendapkan dan dipompa kembali ke bagian inlet bak aerasi dengan pompa sirkulasi lumpur. Air olahan, yakni air yang keluar setelah proses biologis dapat langsung dibuang ke sungai atau saluran umum. Dengan kombinasi proses anaerob dan aerob tersebut selain dapat menurunkan zat organik (BOD, COD), ammonia, deterjen, padatan tersuspensi (SS), phospat dan lainnya.

\subsection{Keunggulan Sistem Biofilter Anaerob - Aerob} Sistem Biofilter Anaerob - Aerob memiliki beberapa keuntungan, yaitu :

a. Air buangan yang melalui media kerikil / sarang tawon yang terdapat pada biofilter mangakibatkan timbulnya lapisan lendir yang menyelimuti media penyangga atau yang disebut biological film. Air limbah yang masih mengandung zat organik yang belum teruraikan pada bak pengendap bila melalui lapisan lendir ini akan mengalami proses penguraian secara biologis. Efisiensi biofilter tergantung dari luas kontak antara air limbah dengan mikroorganisme yang menempel pada permukaan media filter tersebut. Makin luas bidang kontaknya maka efisiensi penurunan konsentrasi zat organiknya (BOD) makin besar. Selain menghilangkan atau mengurangi konsentrasi $B O D$ dan COD, cara ini dapat juga mengurangi konsentrasi padatan tersuspensi atau suspended solids (SS), deterjen (MBAS), ammonium dan posphor.

b. Biofilter juga berfungsi sebagai media penyaring air limbah yang melalui media ini. Sebagai akibatnya, air limbah yang mengandung suspended solids dan bakteri E.coli setelah melalui filter ini akan berkurang konsentrasinya. Efesiensi penyaringan akan sangat besar karena dengan adanya biofilter up flow yakni penyaringan dengan sistem aliran dari bawah ke atas akan mengurangi kecepatan partikel yang terdapat pada air buangan dan partikel

yang tidak terbawa aliran ke atas akan mengendapkan di dasar bak filter. Sistem biofilter anaerob-aerob ini sangat sederhana, operasinya mudah dan tanpa memakai bahan kimia serta sedikit membutuhkan energi. Proses ini cocok digunakan untuk mengolah air limbah rumah tangga dengan kapasitas yang tidak terlalu besar.

c. Dengan kombinasi proses "Anaerob-Aerob", efisiensi penghilangan senyawa phospor menjadi lebih besar bila dibandingankan dengan proses anaerob atau proses aerob saja. Selama berada pada kondisi anaerob, senyawa phosphor anorganik yang ada dalam sel-sel mikrooragnisme akan keluar sebagi akibat hidrolosa senyawa phospor, sedangkan energi yang dihasilkan digunakan untuk menyerap BOD (senyawa organik) yang ada di dalam air limbah. Efisiensi penghilangan BOD akan berjalan baik apabila perbandingan antara BOD dan phospor ( $P$ ) lebih besar 10 (Metcalf and Eddy, 1991). Selama berada pada kondisi aerob, senyawa phospor terlarut akan diserap oleh bakteria atau mikroorganisme dan akan disintesa menjadi polyphospat dengan menggunakan energi yang dihasilkan oleh proses oksidasi senyawa organik (BOD). Dengan demikian dengan kombinasi proses anaerob-aerob dapat menghilangkan BOD maupun phospor dengan baik. Proses ini dapat digunakan untuk pengolahan air limbah dengan beban organik yang cukup besar.

Sedangkan keunggulan proses pengolahan air limbah dengan menggunakan biofilter anaerob aerob antara lain:

a. Pengelolaannya sangat mudah.

b. Biaya operasinya rendah.

c. Lumpur yang dihasilkan relatif sedikit.

d. Dapat menurunkan konsentrasi senyawa nitrogen atau phosphor yang dapat menyebabkan euthropikasi.

e. Suplai udara untuk aerasi relatif kecil.

f. Dapat digunakan untuk air limbah dengan beban BOD yang cukup besar.

g. Dapat menghilangan padatan tersuspensi dengan baik

\section{KESIMPULAN}

Dari hasil pengamatan dan analisis terhadap data kualitas perairan waduk rio - rio, dapat disimpulkan sebagai berikut:

1. Berdasarkan hasil analisis pengujian sampel air waduk rio - rio secara Fisika, Kimia, dan Mikrobiologi, diperoleh beberapa parameter yang melampaui baku mutu, diantaranya adalah Daya Hantar Listrik, COD, Detergent, Coliform, dan Fecal Coli yang menyebabkan air Waduk Rio - Rio menjadi tercemar

2. Dengan menggunakan Metode Indeks Pencemaran, menunjukkan bahwa tingkat pencemaran Waduk Rio - Rio pada periode I tergolong Cemar Sedang dan periode II tergolong Cemar Berat

3. Dari hasil pemantauan, sumber pencemaran Waduk Rio - Rio adalah limbah domestik yang berasal dari aktivitas masyarakat sekitar waduk. Agar dapat menurunkan tingkat pencemaran di Waduk Rio - Rio maka limbah domestik yang dibuang ke waduk perlu diolah terlebih dahulu. 
Salah satu teknologi pengolahan limbah cair domestik adalah Biofilter Anaerob - Aerob.

\section{DAFTAR PUSTAKA}

- Anonim (2001), "Peraturan Pemerintah Republik Indonesia Nomor 82 Tahun 2001", Pengendalian Pencemaran Peruntukan Perikanan dan Peternakan

- Anonim (2003), “Keputusan Menteri Negara Lingkungan Hidup Nomor 115 Tahun 2003", Pedoman Penetuan Status Mutu Air.

- Metclaf And Eddy (1978). " Waste Water Engineering", Mc Graw Hill.

- Said,N.I. (2000). " Pengolahan Air Limbah dengan Proses Biofilter Anaerob-Aerob". Jurnal Teknologi Lingkungan Vol.1 No.2. Jakarta.

- http://www.kelair.bppt.go.id/Publikasi/BukuAirLi mbahDomestikDKI/BAB13UJICOBAIPALpdf /02,Juli,2013/ Uji Coba Ipal Domestik Individual Biofilter Anaerob -Aerob Dengan Media Batu Split 
Tabel Perhitungan Indeks Pencemaran Waduk Rio - Rio Tahun 2015

\begin{tabular}{|c|c|c|c|c|c|c|c|}
\hline \multirow{2}{*}{ PARAMETER } & \multirow{2}{*}{$\begin{array}{c}\text { BAKU MUTU } \\
\text { (Lij) }\end{array}$} & \multicolumn{3}{|c|}{ PERIODE 1} & \multicolumn{3}{|c|}{ PERIODE 2} \\
\hline & & (Cij) & (Cij/Lij) & (Cij/Lij)baru & (Cij) & $(\mathbf{C i j} / \mathbf{L i j})$ & (Cij/Lij)baru \\
\hline DHL & 1000 & 815,67 & 0,816 & 0,816 & 850,00 & 0,850 & 0,850 \\
\hline TDS & 2000 & 426,67 & 0,213 & 0,213 & 455,00 & 0,228 & 0,228 \\
\hline TSS & 200 & 70,00 & 0,350 & 0,350 & 141,50 & 0,708 & 0,708 \\
\hline $\mathrm{pH}$ & 7,25 & 7,90 & & 0,520 & 7,80 & & 0,440 \\
\hline Phosfat & 0,5 & 1,29 & 2,573 & 3,052 & 1,81 & 3,620 & 3,794 \\
\hline Sulfat & 100 & 98,04 & 0,980 & 0,980 & 31,31 & 0,313 & 0,313 \\
\hline Mn & 1,0 & 0,08 & 0,080 & 0,080 & 0,15 & 0,150 & 0,150 \\
\hline $\begin{array}{l}\text { Minyak dan } \\
\text { Lemak }\end{array}$ & 0,0 & 0,16 & 15,667 & 6,975 & 0,32 & 31,500 & 8,492 \\
\hline MBAS & 0,5 & 0,59 & 1,173 & 1,347 & 1,23 & 2,450 & 2,946 \\
\hline Organik & 25 & 53,11 & 2,124 & 2,636 & 47,98 & 1,919 & 2,415 \\
\hline BOD & 20 & 13,49 & 0,675 & 0,675 & 20,06 & 1,003 & 1,007 \\
\hline COD & 30 & 78,43 & 2,614 & 3,087 & 86,28 & 2,876 & 3,294 \\
\hline Koli & 20000 & 229000,00 & 11,450 & 6,294 & 5850000,00 & 292,500 & 13,331 \\
\hline Koli Tinja & 4000 & 77666,67 & 19,417 & 7,441 & 2750000,00 & 687,500 & 15,186 \\
\hline \multicolumn{2}{|r|}{ Nilai Max } & \multicolumn{3}{|r|}{7,441} & \multicolumn{3}{|r|}{15,186} \\
\hline \multicolumn{2}{|c|}{ Nilai Rata - Rata } & \multicolumn{3}{|r|}{2,462} & \multicolumn{3}{|r|}{3,797} \\
\hline \multicolumn{2}{|c|}{ Indeks Pencemaran } & \multicolumn{3}{|r|}{5,542} & \multicolumn{3}{|r|}{11,069} \\
\hline \multicolumn{2}{|r|}{ Kategori } & \multicolumn{3}{|c|}{ Cemar Sedang } & \multicolumn{3}{|r|}{ Cemar Berat } \\
\hline
\end{tabular}

Sumber : Hasil Perhitungan, 2015

Keterangan :

Cij : Konsentrasi hasil pemantauan 
